\title{
Immunolocalization of progesterone receptors in the canine ovary and their relation to sex steroid hormone concentrations
}

\author{
H. Vermeirsch ${ }^{1}$, P. Simoens ${ }^{1}$, M. Coryn ${ }^{2}$ and W. Van den Broeck ${ }^{1}$ \\ ${ }^{1}$ Department of Morphology, Faculty of Veterinary Medicine, Ghent University, \\ Salisburylaan 133, B-9820 Merelbeke, Belgium; and '2Department of Reproduction, \\ Obstetrics and Herd Health, Faculty of Veterinary Medicine, Ghent University, \\ Salisburylaan 133, B-9820 Merelbeke, Belgium
}

The aim of the present study was to describe the normal cellular distribution of progesterone receptors in the canine ovary at different stages of the oestrous cycle. Samples of both ovaries were obtained from 75 healthy adult bitches of various breeds and ages, including five pregnant bitches and three bitches that had just delivered. The presence of progesterone receptors was visualized by immunohistochemistry on paraffin wax sections using a monoclonal antibody. Nuclear staining for progesterone receptors was observed in the surface epithelium, cortical tubules, rete ovarii, follicle cells, thecal cells, luteal cells, granulosa cell cords and ovarian stroma. The staining intensity for progesterone receptors in the follicle cells increased with the stage of follicle development, indicating an intrafollicular role of progesterone in the mechanism of ovulation and luteinization. The stronger staining intensities for progesterone receptors in thecal cells compared with follicle cells may be explained by the fact that thecal cells mediate some effects of steroid hormones on the follicle cells in secondary and tertiary follicles. Little correlation was found between the expression of progesterone receptors in follicle cells and oestradiol, progesterone or testosterone concentrations. This finding indicates a different regulating mechanism for progesterone receptors in canine ovarian follicles compared with other tissues of the genital tract. During pregnancy all groups of ovarian cells had lower staining intensity scores than during the oestrous cycle, although the sex steroid hormone concentrations in pregnant bitches were similar to those in non-pregnant bitches during the luteal phase of the oestrous cycle. The lower expression of progesterone receptors during pregnancy may be due to higher tissue concentrations of progesterone that are not reflected in the serum because of haemodilution and increased metabolism and clearance during pregnancy.

\section{Introduction}

Ovarian steroids regulate ovarian functions; however, it is not clear whether these steroids act directly on ovarian tissues through their steroid receptors and, therefore, are important local regulators of follicle development, or whether they act indirectly via the hypothalamus or the hypophysis (Iwai et al., 1990). Oestrogen receptors and progesterone receptors have been detected in the ovaries of several species using radioligand techniques (Kim and Greenwald, 1987a,b; Vesanen et al., 1991; Vesanen, 1993; Odore et al., 1999), indicating that steroid hormones have various autocrine and paracrine functions in the ovary. In the present study, immunohistochemistry was used to determine the distribution of progesterone receptors in various types of cells in the ovaries of a large group of bitches. To date, the precise localization of progesterone receptors in the canine ovary has not been described. Therefore, the second aim of the present study was to

Email: Hilde.Vermeirsch@rug.ac.be determine whether changes in the distribution of progesterone receptors occurred throughout different stages of the oestrous cycle and whether the presence of progesterone receptors in different groups of ovarian cells was correlated with the serum concentrations of oestradiol, progesterone and testosterone. Knowledge of the localization and expression of progesterone receptors during the oestrous cycle may lead to a better understanding of hormonal regulation of the ovarian cycle and endocrinological ovarian pathology, such as the development of cystic ovaries.

The present study is part of a global investigation on sex steroid receptors in the different tissues of the genital tract of bitches. In earlier studies, the localization of oestrogen receptors (Vermeirsch et al., 1998, 1999) and progesterone receptors (Vermeirsch et al., 2000a) in the uterus was determined throughout the oestrous cycle and related to the serum concentrations of oestradiol, progesterone and testosterone. In addition, the presence of oestrogen receptors and progesterone receptors in canine pregnant uterus and placenta was determined (Vermeirsch et al., 2000b). 


\section{Materials and Methods}

Samples of both ovaries and uterine horns were obtained from 75 healthy adult bitches of various breeds and ages, presented for ovariohysterectomy at the Faculty of Veterinary Medicine of Ghent University and at two veterinary clinics. For each dog, data concerning anamnesis, weight, litters and last pro-oestrus were recorded. The dogs varied in age from 1 to 12 years, and included 22 mongrels, nine Yorkshire terriers, five Maltese, four Labradors, four West Highland white terriers, four Dobermans, three German shepherds, three poodles, two cocker spaniels, two shih tzus, two pinschers, two beagles, one Afghan hound, one bobtail, one boxer, one fox terrier, one French bulldog, one Jack Russell terrier, one keeshond, one Belgian lakenois, one Munsterlander, one bull terrier, one samoyed, one Saint Bernard and one Cairn terrier. The animals were sedated using medetomedine (40-50 $\mu \mathrm{g} \mathrm{kg}^{-1}$ i.m.) (Domitor; Orion Corporation, Espoo) and subsequently anaesthetized with thiopental (8 $\mathrm{mg} \mathrm{kg}^{-1}$ i.v.) (Pentothal; Abbot Laboratories, North Chicago, IL). After intubation, anaesthesia was maintained using halothane. Immediately after excision, the tissue samples were fixed for $48 \mathrm{~h}$ in $3.5 \%(\mathrm{v} / \mathrm{v})$ phosphatebuffered formaldehyde ( $\mathrm{pH}$ 6.7).

All tissue samples were embedded in paraffin wax, and sections of $5 \mu \mathrm{m}$ were cut, mounted on 3-aminopropyltriethoxysilane-coated (Sigma, St Louis, MO) slides and dried overnight at $37^{\circ} \mathrm{C}$. Paraffin wax was removed with xylene; the sections were rehydratated and pre-treated in an Antigen Retrieval Citra Solution (BioGenex, San Ramon). The pre-treatment consisted of heating the slides in a microwave oven for $2 \mathrm{~min}$ at $700 \mathrm{~W}$ and then for 3, 5 and $5 \mathrm{~min}$ at $200 \mathrm{~W}$ with a $5 \mathrm{~min}$ interval between each treatment. After cooling for $30 \mathrm{~min}$ at $4^{\circ} \mathrm{C}$ and rinsing in distilled water, the slides were incubated for $5 \mathrm{~min}$ with $100 \mu \mathrm{l}$ of a $3 \%(\mathrm{v} / \mathrm{v}) \mathrm{H}_{2} \mathrm{O}_{2}$ solution to block endogenous peroxidase activity. Slides were rinsed in Tris-buffered saline and incubated with $100 \mu \mathrm{l}$ of $30 \%(\mathrm{v} / \mathrm{v})$ Tris-buffered saline solution of normal goat serum for $30 \mathrm{~min}$ at $25^{\circ} \mathrm{C}$ to prevent non-specific reactions. All incubations were carried out in a humidified environment. Immunohistochemical detection of progesterone receptors was performed using a monoclonal mouse-anti-human-progesterone receptor antibody (clone 10A9; Medichim, Marseille), which crossreacts with the canine progesterone receptors (Manzel, 1995). Each tissue section was incubated overnight at $4{ }^{\circ} \mathrm{C}$ with $100 \mu \mathrm{l}$ of a 1:300 dilution of the concentrated primary antibody in Tris-buffered saline. After rinsing in Trisbuffered saline, the sections were incubated for $30 \mathrm{~min}$ at $25^{\circ} \mathrm{C}$ with $80 \mu \mathrm{l}$ of a ready-to-use secondary goat-antimouse antibody (Envision TM+; DAKO, Glostrup) coupled to dextrane peroxidase. Finally, after rinsing in Tris-buffered saline, $100 \mu \mathrm{l}$ diaminobenzindine (DAB) chromogen substrate (DAKO) was applied to the sections for $12.5 \mathrm{~min}$. A reaction of $\mathrm{DAB}$ with peroxidase produces a brown staining. Mayer's haematoxylin was applied for $5 \mathrm{~s}$ as a nuclear counterstain. Positive and negative controls were included in each staining procedure. The positive controls were human breast tissue and canine uterine tissue known to be positive for progesterone receptors, whereas the same tissue sections incubated with Tris-buffered saline instead of the primary antibody served as negative controls. Additional controls included canine uterine tissue sections incubated without primary and secondary antibody.

Serum samples collected immediately before surgery were stored at $-20^{\circ} \mathrm{C}$ until assayed for determination of the serum concentrations of the sex steroids using a radioimmunoassay. The concentrations of progesterone, oestradiol and testosterone were measured as described by Coryn et al. (1981), Henry et al. (1987) and Vermeirsch et al. (1999, 2000a).

The stage of the oestrous cycle for each dog was determined as described in studies on steroid receptors in the uterus (Vermeirsch et al., 1999, 2000a). The animals were first classified by macroscopic and histological examination of the ovaries and uterus using the classification of Andersen and Simpson (1973). After this preliminary classification, the animals were classified further according to the serum progesterone concentrations (Concannon, 1986; Concannon et al., 1989). Animals with uterine tissue at a proliferative stage and a progesterone concentration $<1 \mathrm{ng} \mathrm{ml}^{-1}$ were classified as being in pro-oestrus. Animals with uterine tissue at a late proliferative to early secretory stage and a progesterone concentration of $1-10 \mathrm{ng} \mathrm{ml}^{-1}$ were classified as being in oestrus. Metoestrus was divided into an early and a late stage for precise evaluation of progesterone receptors during the period in which the corpus luteum is active. Animals with uterine tissue at a secretory stage were classified as being in early metoestrus when progesterone concentrations were $>10 \mathrm{ng} \mathrm{ml}^{-1}$, and in late metoestrus when progesterone concentrations were $<10 \mathrm{ng} \mathrm{ml}^{-1}$. Animals with uterine tissue at an inactive stage were classified as being in anoestrus. The number of animals and mean serum hormone concentrations at each stage are listed (Table 1). Five bitches were pregnant between day 23 and day 42 of gestation. The day of gestation was estimated using the crown-rump length of the fetuses (Evans, 1993; Vermeirsch et al., 2000b), and three bitches had just delivered, that is, they were at $1-3$ days post partum.

For each dog one tissue section from each ovary was stained for progesterone receptors. The expression of progesterone receptors in the tissue sections was examined three times using a light microscope at $\times 400$ magnification. The microscopist had no knowledge about the animal from which the tissue was obtained. Each group of positively stained cells was given an immunohistochemical total score, which consisted of the sum of an intensity score and a proportional score. The intensity score reflected the intensity of the brown positive staining in the cell nuclei, whereas the proportional score reflected the percentage of cell nuclei that stained positive in the different groups of cells (Table 2). The proportional score was based on all cells of the surface epithelium, rete ovarii and cortical tubules 
Table 1. Number of bitches $(n)$ at each stage of the oestrous cycle and the corresponding mean serum concentrations of sex steroids

\begin{tabular}{|c|c|c|c|c|}
\hline $\begin{array}{l}\text { Stage of the } \\
\text { oestrous cycle }\end{array}$ & $n$ & $\begin{array}{l}\text { Progesterone } \\
\quad\left(\mathrm{ng} \mathrm{ml}^{-1}\right)\end{array}$ & $\begin{array}{c}\text { Oestradiol } \\
\left(\mathrm{pg} \mathrm{m}^{-1}\right)\end{array}$ & $\begin{array}{l}\text { Testosterone } \\
\left(\mathrm{ng} \mathrm{ml}^{-1}\right)\end{array}$ \\
\hline Pro-oestrus & 6 & $0.44 \pm 0.09$ & $19.33 \pm 9.29$ & $0.16 \pm 0.03$ \\
\hline Oestrus & 19 & $3.33 \pm 2.49$ & $12.42 \pm 8.05$ & $0.15 \pm 0.08$ \\
\hline Early metoestrus & 4 & $14.79 \pm 3.64$ & $8.50 \pm 0.71$ & $0.09 \pm 0.06$ \\
\hline Late metoestrus & 8 & $1.11 \pm 0.89$ & $4.67 \pm 4.13$ & $0.09 \pm 0.05$ \\
\hline Anoestrus & 30 & $0.61 \pm 0.56$ & $4.26 \pm 3.49$ & $0.09 \pm 0.04$ \\
\hline
\end{tabular}

Values are mean $\pm \mathrm{SD}$.

Table 2. Immunohistochemical grading scores

\begin{tabular}{ll}
\hline Intensity score & Proportional score \\
\hline 0: no staining & $0:$ no positive nuclei \\
1: weak staining & $1:<1 \%$ positive nuclei \\
2: moderate staining & $2: 1-9 \%$ positive nuclei \\
3: strong staining & $3: 10-32 \%$ positive nuclei \\
4: very strong staining & $4: 33-65 \%$ positive nuclei \\
& $5:>65 \%$ positive nuclei \\
\hline
\end{tabular}

and on representative areas of the other groups of cells. In these representative areas, up to 100 cells were evaluated. Scores were determined in morphologically normal follicles that were classified into primordial, primary, secondary and tertiary follicles according to the criteria listed by the Nomina Histologica (1994). Note that the term 'follicle cells' includes all cells of a given follicle, except for the oocyte and the cells of the theca interna and externa.

A statistical computer software program (Statistix for Windows; Analytical Software, Tallahassee) was used to perform the statistical tests. The non-parametric KruskallWallis test was applied to determine whether there was any significant difference in staining throughout the oestrous cycle or between the different groups of cells. The Bonferroni test was used to determine in which particular stages or groups of cells the staining scores were significantly different from one another. The Spearman rank correlation test was used for determination of correlations between the immunohistochemical scores and the serum hormone concentrations.

\section{Results}

\section{Localization of progesterone receptors}

Immunohistochemistry revealed the presence of progesterone receptors, as indicated by brown staining, in the nuclei of different groups of ovarian cells (Figs 1 and 2), namely the surface epithelium, cortical tubules, rete ovarii, follicle cells, thecal cells, luteal cells, granulosa cell cords and in the ovarian stroma. No staining for progesterone receptors was observed in oocytes or blood vessels. Positive staining was not observed in the negative controls.

\section{Variation of progesterone receptor expression in different groups of ovarian cells}

Significant differences were observed in staining scores between different groups of cells irrespective of the stage of the oestrous cycle (Fig. 3). In the ovarian follicles the staining intensity for progesterone receptors in the follicle cells increased with the stage of the follicle development. The intensity was significantly lower in the primordial and primary follicles compared with the secondary and tertiary follicles $(P<0.01)$. The proportional scores in the cells of different follicles were similar, except for the primordial follicles in which positive cells were observed less frequently $(P<0.01)$. The total scores increased with the stage of follicle development. Primary follicles were significantly less positive for progesterone receptors than were secondary follicles $(P<0.05)$ and tertiary follicles $(P<0.01)$. Primordial follicles were also significantly less positive than were secondary follicles and tertiary follicles $(P<0.01)$. In luteinizing tertiary follicles, the follicle cells had higher staining intensity and total scores than did other tertiary follicles $(P<0.01)$.

The intensity, proportional and total scores of granulosa cell cords, which are thought to originate from atretic secondary follicles, were not significantly different from those of secondary follicles. However, compared with the ovarian stroma, the granulosa cell cords had a lower staining intensity and a higher proportional score $(P<0.01)$.

The other epithelial cells in the ovary, namely, the surface epithelium, cortical tubules and rete ovarii, had different staining intensity scores $(P<0.01)$. The surface epithelium had the lowest staining intensity and the cortical tubules had the highest staining intensity. In the cortical tubules and rete ovarii, nearly all cells stained with the same intensity, whereas the surface epithelium contained negative cells more frequently $(P<0.01)$. These differences were reflected in the total scores. The cortical tubules had higher total scores than did the rete ovarii $(P<0.05)$, whereas the total score of the surface epithelium was lower than that of both other groups of cells $(P<0.01)$.

Cells of the corpora lutea stained with a low intensity, which was intermediate between that of the primary and secondary follicles, and was significantly lower than that of the tertiary follicles $(P<0.01)$. Positive staining was observed less frequently in luteal cells than in follicle cells 

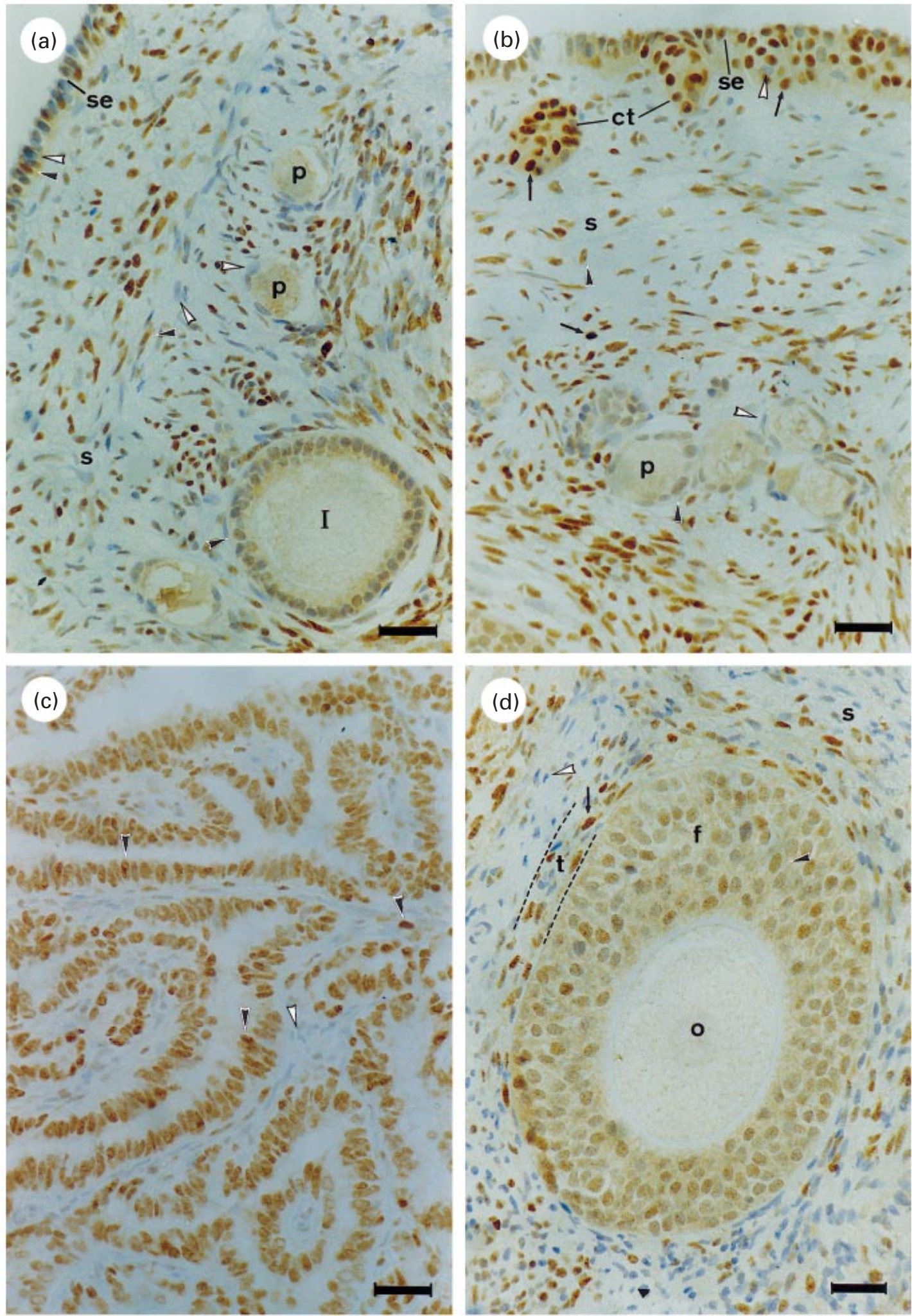

Fig. 1. Immunohistochemical staining for progesterone receptors in different groups of canine ovarian cells. Arrows indicate strong to moderate positive staining; black arrowheads indicate weak positive staining; white arrowheads indicate negative staining. (a,b) Progesterone receptors were expressed in the surface epithelium (se), cortical tubules (ct), stromal cells (s), follicle cells of primordial (p) and primary (I) follicles. (c) The rete ovarii also expressed progesterone receptors. (d) In the secondary follicles no positive staining for progesterone receptors 
$(P<0.01)$ and luteal cells had a lower total score $(P<0.01$; except for the primordial follicles). In old corpora lutea that were generally observed in anoestrus and pro-oestrus, a higher staining intensity was observed than in the other corpora lutea $(P<0.01)$.

The staining scores of the ovarian stroma and the theca externa of tertiary follicles were lower than those of the theca interna of tertiary follicles and the theca layer of secondary follicles $(P<0.01)$. The thecal interna and externa of luteinizing tertiary follicles had lower staining scores compared with other tertiary follicles $(P<0.01$; proportional score of the theca externa $P<0.05)$. In large antral follicles in particular, the expression of progesterone receptors in the theca externa was not distributed evenly, as the theca externa cells located at the side of the ovarian surface stained positive, whereas those located at the medullary side stained negative (for a comparison, see Fig. $2 a, b)$. Positive staining of stromal cells occurred less frequently in the tunica albuginea than it did in the other stromal cells, but the intensity of the staining was similar.

\section{Cyclic variations of expression of progesterone receptors}

Cyclic changes in the staining intensity for progesterone receptors were observed throughout the oestrous cycle (Table 3; Figs 4-6). In groups of cells with significant cyclic changes, the staining intensity for progesterone receptors decreased from pro-oestrus to oestrus, except for the stroma. In the thecal cells of tertiary follicles, granulosa cells of secondary follicles and granulosa cell cords, the staining intensity was lower during oestrus than in any other stage of the oestrous cycle. In the corpus luteum and cortical tubules, the staining intensity was lowest during early metoestrus. The ovarian stroma was an exception as in early metoestrus staining for progesterone receptors was at the strongest intensity.

The proportional scores showed no cyclic variations, except for the corpus luteum and the theca externa of tertiary follicles, in which changes were significant $(P<0.05)$. In the corpus luteum, more cells stained positive during pro-oestrus and anoestrus than during any other stage of the oestrous cycle. The theca externa cells had lowest proportional scores in oestrus and highest scores in late metoestrus.

Cyclic variations in the total scores reflected those in the intensity scores and were only significant for the corpus luteum, the thecal cells of the tertiary follicle and the cortical tubules $(P<0.01)$.

\section{Expression of progesterone receptors during pregnancy and post partum}

During pregnancy all groups of cells had lower staining scores for progesterone receptors than during the oestrous cycle. Except for the rete ovarii and the cortical tubules, all progesterone receptor-positive groups of cells stained with a significantly lower intensity $(P<0.05$ for the granulosa layer of the secondary follicle, theca externa of the tertiary follicle, stroma, epithelium and granulosa cell cords; $P<0.01$ for the other follicle cells, the theca interna cells and the corpora lutea). The proportional score was also lower during pregnancy than during the oestrous cycle $(P<0.01$; epithelium $P<0.05)$, but this difference was not significant for the rete ovarii, cortical tubules and theca interna and externa of the tertiary follicle. As a consequence, the total scores were also lower in pregnant bitches $(P<0.01 ; P<0.05$ for the theca externa of the tertiary follicle and the rete ovarii; not significant for the cortical tubules).

During postpartum anoestrus the staining scores for progesterone receptors in the different groups of ovarian cells were similar to those during the anoestrous stage of the oestrous cycle. No significant differences were found.

\section{Relationships between steroid hormone concentrations and expression of progesterone receptors}

The serum progesterone concentration was negatively correlated with: (i) the staining intensity scores of the cortical tubules $(P<0.01)$, the theca interna of the tertiary follicle, the corpus luteum and the granulosa cells of the secondary follicle $(P<0.05)$; (ii) the proportional scores of the corpus luteum and the theca externa of the tertiary follicle; and (iii) the total scores of the cortical tubules, the corpus luteum and the theca externa of the tertiary follicle $(P<0.05)$. In contrast, the progesterone concentration was positively correlated with the staining intensity score of the ovarian stroma $(P<0.05)$.

The oestradiol concentration was positively correlated with: (i) the intensity scores of the surface epithelium, stroma $(P<0.01)$ and cortical tubules $(P<0.05)$; (ii) the proportional scores of the surface epithelium $(P<0.05)$; and (iii) the total scores of the surface epithelium $(P<0.01)$ and stroma $(P<0.05)$. In contrast, the oestradiol concentration was negatively correlated with the proportional and total scores of the theca interna of tertiary follicles $(P<0.01)$.

The testosterone concentration was negatively correlated with: (i) all staining scores of the theca interna and externa of tertiary follicles $(P<0.01)$; (ii) the proportional score of the rete ovarii $(P<0.01)$; and (iii) the total score of the primordial follicles $(P<0.05)$. In contrast, the testosterone concentration was positively correlated with all staining scores of the corpus luteum $(P<0.01)$.

\section{Discussion}

Immunohistochemistry revealed a species-specific expression of progesterone receptors in the ovary and localized progesterone receptors in the surface epithelium (Hild-Petito

was observed in the oocyte (o), but weak staining was observed in the follicle cells $(\mathrm{f})$ and moderate staining in the thecal cells $(\mathrm{t})$. Some stromal cells (s) were positive. Scale bars represent $32 \mu \mathrm{m}$. 

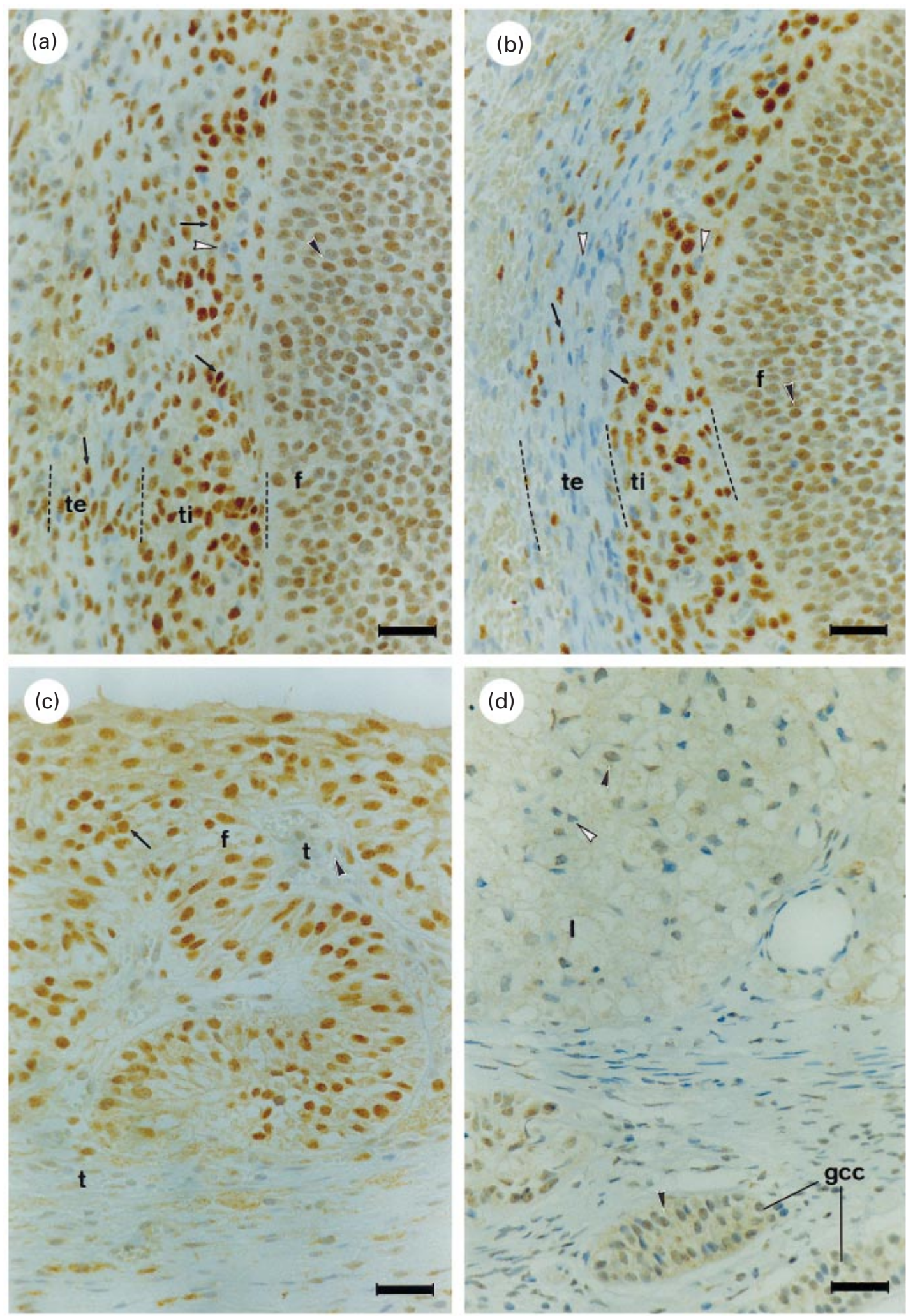

Fig. 2. Immunohistochemical staining for progesterone receptors in canine tertiary follicles and corpora lutea. Arrows indicate moderate positive staining; black arrowheads indicate weak positive staining; white arrowheads indicate negative staining. (a) In the follicular wall of large antral follicles at the side of the ovarian surface, weak positive staining was observed in the follicle cells ( $f$ ) and moderate staining in cells of the theca externa (te) and the theca interna (ti). (b) In the follicular wall of large antral follicles at the medullary side, weak positive staining 
et al., 1988; Korte and Isola, 1988; Press and Greene, 1988; Slomczynska et al., 2000), follicle cells (Hild-Petito et al., 1988; Korte and Isola, 1988; Iwai et al., 1990; Revelli et al., 1996; Slomczynska et al., 2000), thecal cells (Hild-Petito et al., 1988; Korte and Isola, 1988; Iwai et al., 1990; Suzuki et al., 1994; Revelli et al., 1996; Slomczynska et al., 2000), stromal cells (Hild-Petito et al., 1988; Korte and Isola, 1988; Press and Greene, 1988; Iwai et al., 1990; Suzuki et al., 1994; Revelli et al., 1996) and luteal cells (Hild-Petito et al., 1988; Korte and Isola, 1988; Press and Greene, 1988; Iwai et al., 1990; Suzuki et al., 1994; Revelli et al., 1996; Duffy et al., 1997; Sasano and Suzuki, 1997; Slomczynska et al., 2000). Furthermore, progesterone receptor mRNA has been detected in the surface epithelium, in follicle cells (Chandrasekhar et al., 1994) and in luteal cells (Chandrasekhar et al., 1994; Misao et al., 1998). In the present study in dogs, progesterone receptors were observed in all these groups of cells and in the granulosa cell cords, rete ovarii and cortical tubules, indicating that progesterone has a direct influence on ovarian tissue. The absence of progesterone receptor expression in oocytes and blood vessels has also been noted in the human ovary (Revelli et al., 1996).

The presence of progesterone receptors in granulosa cell cords in the canine ovary is consistent with the presence of progesterone receptors in the granulosa cell layer of secondary follicles from which the granulosa cell cords originate (Anderson and Simpson, 1973). The rete ovarii has a secretory capability in several species (Wenzel and Odend'hal, 1985), and it may have a role in the control of meiosis and be the source of follicle cells (Wenzel and Odend'hal, 1985). The reasons for its progesterone receptivity and its precise function have not been determined. Progesterone receptors were also expressed in the cortical tubules, which are invaginations of the surface epithelium that are common in adult ovaries of some species (Mossman and Duke, 1973; Mülling et al., 1998), including dogs (Anderson and Simpson, 1973). It has been suggested that these cortical tubules are a source of oocytes (Mossman and Duke, 1973), interstitial cells (Mülling et al., 1998) or follicle cells (Pineda, 1989), or that they are the remains of the fetal germinal strands (Ellenberger, 1911). Alternatively, it is possible that the cortical tubules result from entrapment of ovarian surface epithelium within the ovarian stroma after ovulation, forming an ovarian inclusion cyst, as observed in human ovaries (Resta et al., 1987). This suggestion is more likely as the cortical tubules become more prominent as the animal advances in age (Anderson and Simpson, 1973) and show similar cyclic changes in the expression of progesterone receptors as the surface epithelium.

In the canine ovary, the staining for progesterone receptors increases with the development of the follicles. In primates, follicles that developed beyond the primary stage
Table 3. Significance of cyclic changes in staining intensity for progesterone receptors in the canine ovary

\begin{tabular}{ll}
\hline Sample & Significance \\
\hline
\end{tabular}

Follicle cells of primordial follicles

Follicle cells of primary follicles

Follicle cells of tertiary follicles

Theca layer of secondary follicles

Rete ovarii

Surface epithelium

Follicle cells of the secondary follicles

Granulosa cell cords

Corpus luteum

Ovarian stroma

Theca externa cells of the tertiary follicles

Theca interna cells of the tertiary follicles $\quad P<0.01$ Cortical tubules

no longer expressed progesterone receptors until after the surge of $\mathrm{LH}$, when the luteinizing preovulatory follicles again stained positive for progesterone receptors (HildPetito et al., 1988). Revelli et al. (1996) observed weak to moderate staining for progesterone receptors in human follicle cells. Other studies observed no staining for progesterone receptors in human preantral follicles (Iwai et al., 1990; Suzuki et al., 1994), whereas cells of the dominant follicle showed marked positive staining at the time of ovulation (Iwai et al., 1990). In all species examined to date, luteinizing follicle cells expressed progesterone receptors during the short interval between the preovulatory gonadotrophin surge and ovulation (Park and Mayo, 1991; Revelli et al., 1996; Slomczynska et al., 2000). In dogs, cells of antral follicles and luteinizing follicles stained with the strongest intensity, especially during oestrus when ovulations occur. This finding indicates that progesterone has an important intrafollicular role in modulating follicular growth and granulosa cell functions, as in other species. However, the exact role of progesterone has not been established (Hsueh et al., 1984). The expression of progesterone receptors in preovulatory follicles may be critical for successful ovulation (Pinter et al., 1996; Revelli et al., 1996; Duffy et al., 1997) and luteinization (Revelli et al., 1996; Duffy et al., 1997), and the maintenance of luteal structure and function (Duffy et al., 1997). This notion is supported by the fact that female progesterone receptor -/- homozygote mice are infertile because no differentiation of granulosa cells to luteinized cells occurs in their ovaries and no ovulations occur (Revelli et al., 1996).

The presence of progesterone receptors in corpora lutea indicates that ovarian steroids are important for the

was observed in the follicle cells ( $\mathrm{f}$ ) and moderate staining in the cells of the theca interna (ti), whereas most theca externa cells (te) were negatively stained. (c) In luteinizing tertiary follicles, thecal cells (t) were weakly positive and follicle cells ( $f$ ) were moderately positive. (d) Cells of the granulosa cell cords (gcc) and the corpus luteum (I) were weakly positive for progesterone receptors. Scale bars represent $32 \mu \mathrm{m}$. 

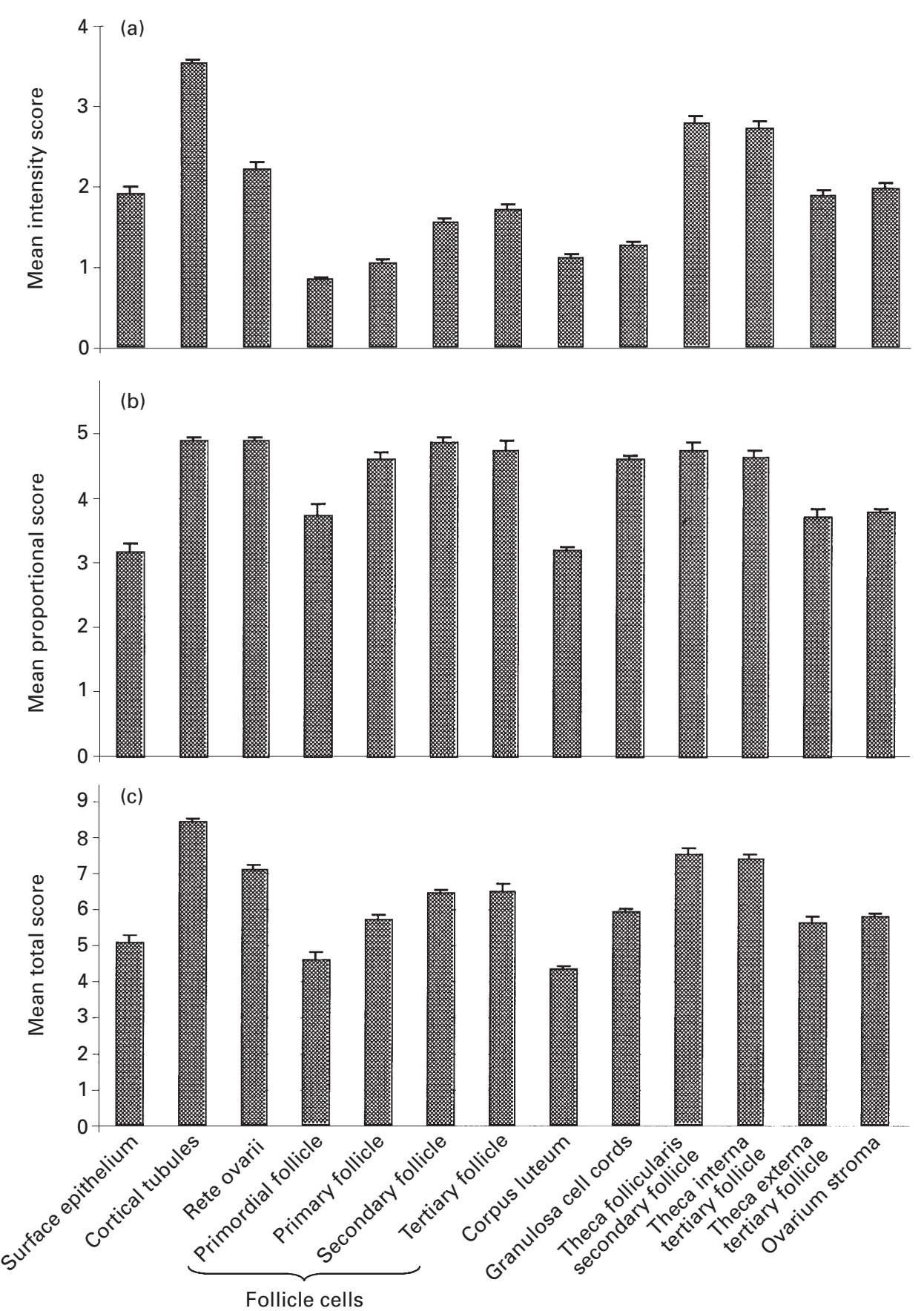

Fig. 3. Mean $( \pm$ SEM) staining scores for progesterone receptors in different groups of ovarian cells, irrespective of the stage of the oestrous cycle, in histological sections of both ovaries of 75 bitches. (a) Mean intensity score: $0=$ no staining; 4 = very strong staining. (b) Mean proportional score: $0=$ no positive nuclei; $5=>65 \%$ positive nuclei. (c) Total score: sum of intensity score and proportional score.

regulation of the corpus luteum (Revelli et al., 1996). Progesterone acts locally to regulate the proliferation and development of luteinized granulosa and thecal cells (Sasano and Suzuki, 1997). In primates, expression of progesterone receptors in corpora lutea is greatest during the mid-luteal stage (Hild-Petito et al., 1988; Iwai et al., 1990; Suzuki et al., 1994; Revelli et al., 1996; Sasano and
Suzuki, 1997; Misao et al., 1998). In general, the expression of progesterone receptors in the canine corpora lutea was low compared with other groups of cells, as in rabbits (Korte and Isola, 1988), and was negatively correlated with the progesterone concentrations, which is in contrast to findings in monkeys (Hild-Petito et al., 1988) and pigs (Slomczynska et al., 2000). This low expression of 


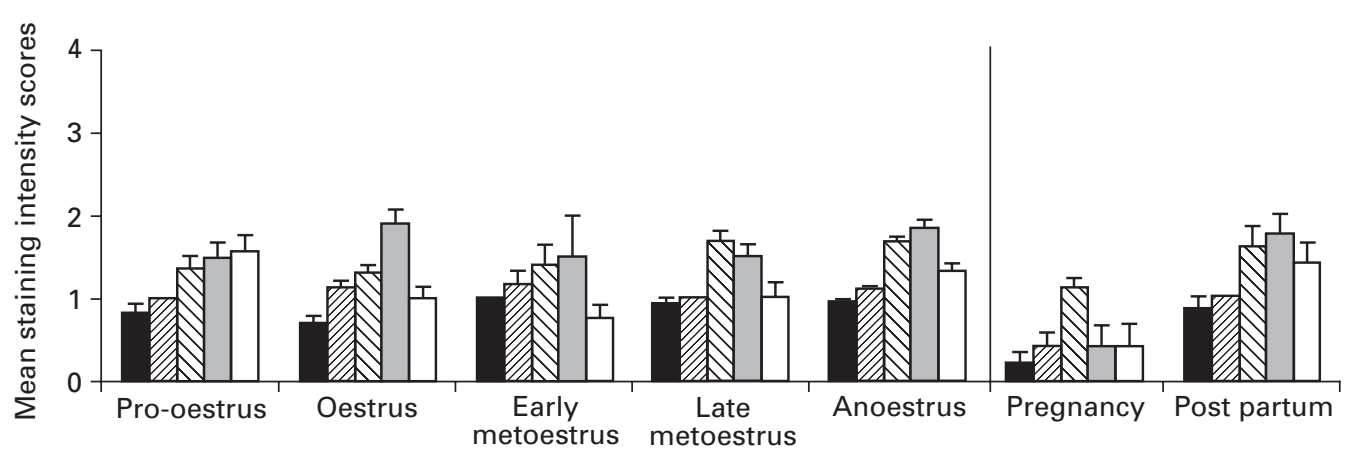

Fig. 4. Mean ( \pm SEM) staining intensity scores $(0=$ no staining; $4=$ strong intensity staining) for progesterone receptors in different stages of follicular development (ם: primordial follicle; $\square$ : primary follicle; $\nabla$ : secondary follicle; $\square$ : tertiary follicle) and in corpora lutea ( $\square$ ) in 75 bitches grouped by the stage of the oestrous cycle.

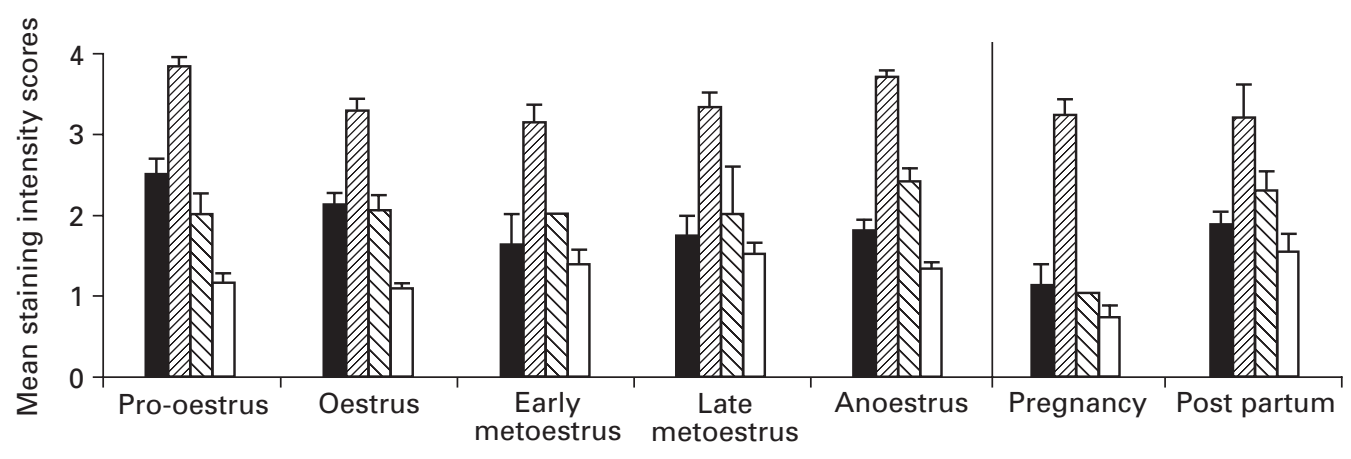

Fig. 5. Mean ( \pm SEM) staining intensity scores $(0=$ no staining; 4 = very strong staining) for progesterone receptors in the ovarian epithelia (ద: surface epithelium; $\nabla$ : cortical tubules; $\nabla$ : rete ovarii) and in granulosa cell cords $(\square)$ in 75 bitches grouped by the stage of the oestrous cycle.

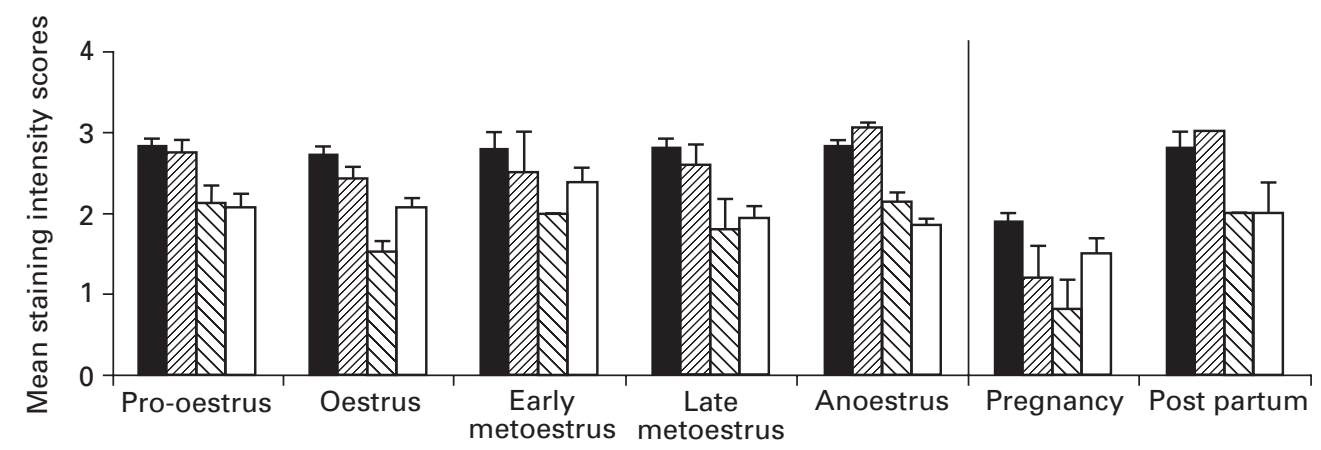

Fig. 6. Mean ( \pm SEM) staining intensity scores $(0=$ no staining; $4=$ very strong staining $)$ for progesterone receptors in ovarian stromal cells ( $\square$ : theca follicularis; $\square$ : theca interna; $\nabla$ : theca externa; $\square$ : ovarian stroma) in 75 bitches grouped by the stage of the oestrous cycle.

progesterone receptors may be due to a negative effect of progesterone on production of progesterone receptors. However, it is possible that fewer progesterone receptors are required in the corpus luteum to enable progesterone to act, as a high progesterone concentration is present in this tissue. Higher staining scores were observed in old corpora lutea in bitches at anoestrus and pro-oestrus, which could be the consequence of a decrease in progesterone production. According to Iwai et al. (1990), the weaker staining for progesterone receptors in the human corpus luteum of pregnancy compared with that in the periodical corpus luteum may be associated with the downregulation of progesterone receptors by endogenous progesterone and/or with the degeneration of luteal cells. Similarly, in dogs, a weaker staining for progesterone receptors was observed in the corpora lutea during pregnancy. However, 
in dogs, the lifespans of corpora lutea during the luteal stage of the oestrous cycle and during pregnancy are nearly similar, and the concomitant increase in serum progesterone concentrations is as high and prolonged in nonpregnant as in pregnant bitches (Concannon, 1986). However, Gudermuth et al. (1998) reported pregnancyspecific increases in faecal concentrations of progesterone, oestradiol and testosterone in dogs. This finding indicates that the corpora lutea of pregnant bitches synthesize and secrete more steroids than those in non-pregnant bitches, but this increase in steroids is not reflected in the serum because of increased haemodilution, metabolism and clearance during pregnancy. Thus, in dogs, increased tissue concentrations of progesterone may be the reason for significantly weaker staining for progesterone receptors in nearly all groups of ovarian cells during pregnancy. In pregnant compared with non-pregnant bitches there is also a marked increase in the concentration of FSH (Reimers et al., 1978). This finding raises the question of whether these increased $\mathrm{FSH}$ concentrations may participate in the decrease in progesterone receptor expression in the canine ovary, as progesterone receptor expression does not occur in rabbit granulosa cells treated with progesterone after $\mathrm{FSH}$ treatment (Iwai et al., 1991).

In the canine ovary, the expression of progesterone receptors in thecal cells of secondary follicles and theca interna cells of tertiary follicles was more prominent than that in follicle cells and was correlated with at least two different sex steroid hormones, in contrast to follicle cells. Furthermore, theca interna cells, which are more closely related to follicle cells than theca externa cells, showed stronger staining for progesterone receptors, as observed in pigs (Slomczynska et al., 2000). This finding indicates that progesterone exerts its influence on follicle cells also via thecal and stromal cells, particularly via the theca cell layer lying closest to the follicle cells. This could also explain why positive staining was observed less frequently in stromal cells of the tunica albuginea, which is not as closely related to the follicles. Similar indications for stromalepithelial interactions were found in the canine endometrium (Vermeirsch et al., 1998, 1999, 2000a). The possibility of a paracrine action of ovarian steroids on follicles and corpora lutea, mediated through stromal steroid receptors and steroid-linked local factors, has also been suggested in humans (Revelli et al., 1996). There are several examples of interaction between thecal and follicle cells. The biosynthesis of oestrogens in follicle cells requires interaction with neighbouring thecal cells that provide steroid precursors (Hsueh et al., 1984; Sasano and Suzuki, 1997). Early follicular growth may be regulated by progesterone via stromal and thecal cells (Hild-Petito et al., 1988). The thecal cells may secrete factors that promote granulosa cell growth or differentiation (Hsueh et al., 1984). Furthermore, progesterone via progesterone receptors in thecal cells might facilitate rapid growth of preovulatory follicles by remodelling of the extracellular matrix (Yoshimura and Bahr, 1991). Progesterone is also thought to be important in the mechanism of $\mathrm{LH}$-induced follicular rupture, but it remains to be determined where this progesterone action occurs. Just before ovulation, localized processes of digestion and dissociation of the collagen fibres result in an opening in the follicular wall and the formation of the stigma and follicular rupture (Morioka et al., 1989). In the present study, progesterone receptors in the theca externa of large preovulatory follicles were more prominent at the side of the ovarian surface compared with the medullary side. If these progesterone receptors play a role in follicular rupture it could explain why stigma formation and rupture always occur at the apex of the follicle, although weakening of the follicular wall occurs throughout the entire wall (Morioka et al., 1989). However, an explanation is required as to how this difference in progesterone expression can occur.

The serum concentrations of oestradiol, progesterone and testosterone showed few correlations with the expression of progesterone receptors in the ovarian follicles, although oestrogen is considered to be the primary regulator of progesterone receptor expression in many tissues (Katzenellenbogen, 1980; Hild-Petito et al., 1988; Revelli et al., 1996). There are indications that expression of progesterone receptors in the ovary is not under direct oestrogenic control, although this does not exclude a indirect role of oestrogen in ovarian progesterone receptor expression (Pinter et al., 1996). In follicle cells in particular, the expression of progesterone receptors is regulated by the action of LH together with gonadotrophin in humans and primates (Iwai et al., 1991; Duffy et al., 1996). Thus, there is an important contrast between progesterone receptor induction in the ovarian follicles, which is regulated by gonadotrophins via membrane receptors, and receptor induction in other well known progesterone target tissues, such as the uterus, which is regulated by oestrogens via nuclear receptors (Pinter et al., 1996). This contrast in progesterone receptor induction mechanisms has been observed in several species and the present study indicates that it is also present in dogs.

The authors are grateful to J. De Schepper, C. De Prest, P. Herbots, and P. and J. Vander Cruyssen for assistance with the sample collections. In the Department of Morphology, Ghent University, the authors extend their thanks to A. Hellemans and L. Standaert for the immunohistochemical staining of the tissue sections, and R. De Moor for photography.

\section{References}

Andersen AC and Simpson ME (1973) The Ovary and Reproductive Cycle of the Dog (Beagle) pp 1-282. Geron-X, Palo Alto, CA

Chandrasekhar YA, Melner MH, Nagalla SR and Stouffer RL (1994) Progesterone receptor, but not estradiol receptor messenger ribonucleic acid is expressed in luteinizing granulosa cells and the corpus luteum in rhesus monkeys Endocrinology 135 307-314

Concannon PW (1986) Canine pregnancy and parturition Veterinary Clinics of North America: Small Animal Practice 16 453-475

Concannon PW, McCann JP and Temple M (1989) Biology and endocrinology of ovulation, pregnancy and parturition in the dog Journal of Reproduction and Fertility Supplement 39 3-25 
Coryn M, De Moor A, Bouters R and Vandeplassche M (1981) Clinical, morphological and endocrinological aspects of cryptorchidism in the horse Theriogenology 16 489-496

Duffy DM, Molskness TA and Stouffer RL (1996) Progesterone receptor messenger ribonucleic acid and protein in luteinized granulosa cells of rhesus monkeys are regulated in vitro by gonadotropins and steroids Biology of Reproduction $\mathbf{5 4}$ 888-895

Duffy DM, Wells TR, Haluska GJ and Stouffer RL (1997) The ratio of progesterone receptor isoforms changes in the monkey corpus luteum during the luteal phase of the menstrual cycle Biology of Reproduction 57 693-699

Ellenberger W (1911) In Handbuch der Vergleichenden Mikroskopischen Anatomie der Haustiere pp 35-36 562 Verlagsbuchhandlung Paul Parey, Berlin

Evans HE (1993) Prenatal development. In Miller's Anatomy of the Dog pp 44-48 Ed. HE Evans. WB Saunders Company, Philadelphia

Gudermuth DF, Concannon PW, Daels PF and Lasley BL (1998) Pregnancy specific elevations in fecal concentrations of estradiol, testosterone and progesterone in the domestic dog (Canis familiaris). Theriogenology $\mathbf{5 0}$ 237-248

Henry M, Figueiredo AEF, Palhares MS and Coryn M (1987) Clinical and endocrine aspects of the oestrous cycle in donkeys (Equus asinus). Journal of Reproduction and Fertility Supplement 35 297-303

Hild-Petito S, Stouffer RL and Brenner RM (1988) Immunocytochemical localization of estradiol and progesterone receptors in the monkey ovary throughout the menstrual cycle Endocrinology 123 2896-2905

Hsueh AJW, Adashi EY, Jones PBC and Welsh TH, Jr (1984) Hormonal regulation of the differentiation of cultured ovarian granulosa cells Endocrine Reviews 5 76-127

Iwai T, Nanbu Y, Iwai M, Taii S, Fujii S and Mori T (1990) Immunohistochemical localization of oestrogen receptors and progesterone receptors in the human ovary throughout the menstrual cycle Virchows Archiv A 417 369-375

Iwai T, Fujii S, Nanbu Y, Nonogaki H, Konishi I, Mori T and Okamura H (1991) Effect of human chorionic gonadotropin on the expression of progesterone receptors and estrogen receptors in rabbit ovarian granulosa cells and the uterus Endocrinology 129 1840-1848

Katzenellenbogen B (1980) Dynamics of steroid hormone receptor action Annual Review of Physiology 42 17-35

Kim I and Greenwald GS (1987a) Effects of estrogens on follicular development and ovarian and uterine estrogen receptors in the immature rabbit, guinea-pig and mouse Endocrinologia Japonica 34 871-878

Kim I and Greenwald GS (1987b) Estrogen receptors in ovary and uterus of immature hamster and rat: effects of estrogen Endocrinologia Japonica 34 45-53

Korte JM and Isola JJ (1988) An immunocytochemical study of the progesterone receptor in rabbit ovary Molecular and Cellular Endocrinology 58 93-101

Manzel O (1995) Immunohistochemische Darstellung der Östrogen und Progesteron-rezeptoren in Gewebeschnitten des Hundes PhD Thesis, University of Hannover

Misao R, Nakanishi Y, Iwagaki S, Fujimoto J and Tamaya T (1998) Expression of progesterone receptor isoforms in corpora lutea of human subjects: correlation with serum oestrogen and progesterone concentrations Molecular Human Reproduction 4 1045-1052

Morioka N, Zhu C, Brannstrom M, Woessner JF and LeMaire WJ (1989) Mechanism of mammalian ovulation Progress in Clinical and Biological Research 294 65-85

Mossman HW and Duke KL (1973) Comparative morphology. In Comparative Morphology of the Mammalian Ovary pp 118-125. The University of Wisconsin Press, Wisconsin

Mülling C, Christian B and Budras K-D (1998) Subsurface crypts and interstitial cells in the ovary of the seal (Phoca vitulina vitulina): light and electron microscopic findings Italian Journal of Anatomy and Embryology 103 (Supplement 1) 167-181

Nomina Histologica (1994) International Committee on Veterinary Histological Nomenclature 2nd Edn pp 38. Cornell, New York

Odore R, Re G, Badino P, Donn A, Vigo D, Biolatti B and Girardi C (1999) Modifications of receptor concentrations for adrenaline, steroid hormones, prostaglandin $\mathrm{F}_{2 \alpha}$ and gonadotropins in hypophysis and ovary of dairy cows with ovarian cysts Pharmacological Research 39 297-304

Park OK and Mayo KE (1991) Transient expression of progesterone receptor mRNA in ovarian granulosa cells after the preovulatory LH-surge Molecular Endocrinology 5 967-978

Pineda MH (1989) Female reproductive system. In Veterinary Endocrinology and Reproduction pp 303-354 Ed. LE McDonald. Lea and Febiger, Philadelphia

Pinter JH, Deep C and Park-Sarge O-K (1996) Progesterone receptors: expression and regulation in the mammalian ovary Clinical Obstetrics and Gynecology 39 424-435

Press MF and Greene GL (1988) Localization of progesterone receptor with monoclonal antibodies to the human progestin receptor Endocrinology 122 1165-1175

Reimers TJ, Phemister RD and Niswender GD (1978) Radioimmunological measurement of follicle stimulating hormone and prolactin in the dog Biology of Reproduction 19 673-679

Resta L, De Benedictic G, Scordari MD, Orlando E, Borraccino V and Milillo F (1987) Hyperplasia and metaplasia of ovarian surface epithelium in women with endometrial carcinoma. Suggestion for a hormonal influence in ovarian carcinogenesis Tumori 73 249-256

Revelli A, Pacchioni D, Cassoni P, Bussolati G and Massobrio M (1996) In situ hybridization study of messenger RNA for estrogen receptor and immunohistochemical detection of estrogen and progesterone receptors in the human ovary Gynecological Endocrinology 10 177-186

Sasano H and Suzuki T (1997) Localization of steroidogenesis and steroid receptors in human corpus luteum Seminars in Reproductive Endocrinology 15 345-351

Slomczynska M, Krok M and Pierscinski A (2000) Localization of the progesterone receptor in the porcine ovary Acta Histochemica 102 183-191

Suzuki T, Sasano H, Kimura N, Tamura M, Fukaya T, Yajima A and Nagura H (1994) Immunohistochemical distribution of progesterone, androgen and oestrogen receptors in the human ovary during the menstrual cycle: relationship to expression of steroidogenic enzymes Human Reproduction 9 1589-1595

Vermeirsch H, Simoens P and Lauwers H (1998) Variation in the estrogen receptor content of canine uterine tissue throughout the estrous cycle Italian Journal of Anatomy and Embryology 103 (Supplement 1) 267-275

Vermeirsch H, Simoens P, Lauwers H and Coryn M (1999) Immunohistochemical detection of estrogen receptors in the canine uterus and their relation to sex steroid hormone levels Theriogenology 51 729-743

Vermeirsch H, Simoens P, Hellemans A, Coryn M and Lauwers H (2000a) Immunohistochemical detection of progesterone receptors in the canine uterus and their relation to sex steroid hormone levels Theriogenology $53773-788$

Vermeirsch H, Simoens P and Lauwers H (2000b) Immunohistochemical detection of the estrogen receptor $\alpha$ and progesterone receptor in the canine pregnant uterus and placental labyrinth Anatomical Record 260 42-50

Vesanen M (1993) Bovine uterine, cervical and ovarian cytosol estrogen and progesterone receptor concentrations in cystic ovarian disease Acta Veterinaria Scandinavica 34 35-43

Vesanen M, Isomaa V, Alanko M and Vihko R (1991) Bovine uterine, cervical and ovarian estrogen and progesterone receptor concentrations Animal Reproduction Sciences 26 61-71

Wenzel JGW and Odend'hal S (1985) The mammalian rete ovarii: a literature review Cornell Veterinarian 75 411-425

Yoshimura Y and Bahr JM (1991) Localization of progesterone receptors in pre- and postovulatory follicles of the domestic hen Endocrinology 128 $323-330$

Received 20 October 2000.

First decision 2 January 2001.

Accepted 7 March 2001. 
H. Vermeirsch et al. 